\title{
Transnational Engagements: Women's Experiences of Menopause
}

\author{
Edited by Milena Bacalja Perianes and Elizabeth Arveda Kissling
}

\section{BACKGROUND}

The questions that form the basis of these discussions were inspired by a conversation about menopause that Elizabeth had many years ago with her closest aunt, who was near her fiftieth birthday at the time. Aunt Patricia is the youngest of five sisters (including Elizabeth's mother) and had sought information and advice to prepare for menopause from her older sisters and was frustrated by their responses. 'They all say that it was nothing or they don't remember!' she told Elizabeth in disbelief. 'How is that possible?' Even knowing that experiences of menopause are highly variable, Elizabeth agreed that it seemed unlikely that all four women had completely uneventful transitions, with none of the common signs they had both read about: irregular or heavier periods, hot flashes, night sweats, headaches, mood changes, insomnia, dry skin, or weight gain. Nevertheless, Patricia - and Elizabeth, ten years later-was left to her own resourcefulness to navigate menopause.

As chief innovation and research officer of the international organization Menstrual Health Hub, Milena managed connections with NGO directors, health practitioners, and other community leaders who facilitated conversations with participants in four nations to explore questions about menopause knowledge and experiences. We are extremely grateful for their assistance and insight and especially appreciative of the women and men who spoke with them about menopause. As readers will soon learn, this was not an easy task for many of the participants or questioners.

The first discussion comes from a transcript Shardi Nahavandi sent us of a conversation about menopause between her and her Persian mother (57). Her mother grew up in a traditional, rather conservative family in Iran. She now lives in London, and Shardi grew up between London and Tehran. 
Shardi reported that talking to her mother about menopause and her health was an emotional and awkward conversation, and not because it was in Farsi and she translated it into English for our benefit.

I found the difficulty not in the physical language barrier, but the ability for her to express herself, and me to really understand her experiences. If I am honest, my mum was more open than me. I almost didn't want to hear what she had to say because it was painful to think about her in pain and distress. I don't know how to help her and in our culture it's not appropriate for a daughter to talk to her mother about these experiences. I've thought about it a lot since we spoke.

Our second source is a conversation Swetha Sridhar recorded between three Indian women from one family: a grandmother (76), her daughter (55), and her granddaughter, Swetha (27), the interviewer. Her grandmother grew up in Kerala, a small state on the western coast of India. She experienced menarche and menopause in the same house. Her daughter, Swetha's mother, traveled the world, finally landing on the opposite coast of India, in the city of Chennai, where she dealt with both the onset of menopause and widowhood at the same time.

A third source comes from Ursula Maschette Santos, who works in health promotion for women and girls. She conducted a group interview with three women (48-57) in various phases of their menopause transition from her community in São Paulo, Brazil.

Finally, Jennifer Poole conducted a focus group discussion with 17 participants of the NGO Medical Services Pacific in Fiji. The 11 women and 6 men represent the two largest ethnic groups of Fiji: native Fijians or Melanesians (Itaukei) and Indo-Fijians, who have Indian descent.

\section{Meanings of Menopause}

Our Persian participant succinctly summarized her view of menopause in Iran: 'It is very negative, no one likes to talk about it and everyone wants to pretend such a thing doesn't exist.' Itaukei women of Fiji did not necessarily view menopause as positive or negative within their community, just as something that happened: 'Nothing else changes.' Itaukei women, however, acknowledged that menopause is a taboo subject, stating it is only discussed between close female relatives and that men were not included in discussions of women's health. One woman said shame is associated with women's health in general, and 'no one wants to talk about it.' Another said menopause is not spoken about at all: 'You only learn about menstruation, and then menopause as you go through it.' Women in Iran and Fiji sound just like Elizabeth's American aunties!

Jennifer Poole told us that the community members she spoke with stated they did not know how menopause was understood in the community because 'no one ever spoke about it publicly.' She found this especially 
salient for Indo-Fijian women, whose cultural norms continue to support silence around menstrual and vaginal health. When asked whether a woman's position in society changes as a result of menopause or if it changes the way they see themselves, a 55-year-old woman from India responded, 'It's not publicized. At least not in our community. How would anyone know? Unlike when you get your period first, there is some little bit of celebration or whatever, when you stop your period, there is no announcement or public gathering.'

More specifically, women of several nations and communities discussed menopause in terms of the end of reproductive life, as a sign of aging, or both:

It means women are old! (Fiji)

Menopause means old age! (Laughs.) I don't think there are any positive or negative connotations as such. Probably because we don't talk about it at all. But when I was reading about it, I realized that there are many associated things that can make life tiresome, like hot flashes and dry skin. I've only heard older women talk about this, but not menopause itself. (India)

Women have very little value here. After menopause, well, this makes us much less valuable. When you are young, women are seen as reproductive machines and then with menopause you completely lose that one function that society associates with you. We lose the little value we had. (Iran)

It is very sad [that there are] stigmas and taboos around menopause in our society. With the menopause we start to feel old, like a grandma. It gets worse because the children you have, your sons, expect you to look after your grandchildren and not to take care of yourself, your body. (Brazil)

We as women do not usually have a good position in society, our position is to be mothers, and with menopause it doesn't get any better, even if your children are already adults. I have already heard the phrase, "Come on your phase as a young lady has gone, do not use this short skirt, you have to behave yourself in this way, you are an old lady now." The push back women receive happens in all different stages of life, however, it does not stop with the onset of menopause. Society keeps pushing women to behave in certain ways, saying how she should dress up, behave and live. (Brazil)

As the final quotation shows, for some women reaching the age of menopause is accompanied by warnings or advice of how a proper older woman should behave: 'Be quiet, not sexy,' as one Brazilian respondent summarized. Even though their reproductive years are past, women in Brazil still experience the pressure to look and act like a good mother. One woman in Fiji felt her value in society was diminished, as she was still working outside the home after menopause, which is unusual in Fiji. She was teased by her sisters-in-law 
about what she wore to work and about 'still trying to find a man,' which was very upsetting to her. Other women in the Fiji focus group spoke of not wanting to be viewed as 'old grandmas' with no sex drive, saying, 'Women still want to be sexy and noticed, even if their sex drive is down.' At the same time, there was significant concern in the group regarding sexual obligations in heterosexual relationships, and the ways 'men don't understand why we don't have sexual desire.' This created some friction in relationships, with some women feeling unable to talk with their partners about sex and menopausal changes: 'Relationships can change between husband and wife because of decreased sexual desire. Some men don't listen, think women are making excuses.'

Women everywhere also praised the many benefits of menopause. The end of reproductive capacity represents sexual freedom for some; one Brazilian woman said she is now free to 'explore my sexuality without the pressure and fear of getting pregnant.' To some women, menopause means the onset of their sexual liberation, where they feel freer to explore their sexuality in many different ways. 'Sexuality means freedom during my menopause,' said one of the women from Brazil. 'I feel freer to have a sexual relationship with a person and this opens other types of freedom. What was once was a barrier to me, now no longer is. I am more open now and much more open-minded.' Another Brazilian mentioned that her 60-year-old friends carry condoms in their bags, something unthinkable some years ago.

Menopause brings other freedoms as well. Indo-Fijian women stated there were various religious taboos around menstruation that impacted both menstruation and menopause: 'A Muslim woman cannot pray while bleeding, for example!' Postmenopausal women do not face this restriction. One woman from India said, 'In many ways, it gives us freedom, where otherwise you may not be allowed in public spaces, you can now do what you like.' Another Indian woman said, 'A lot of us felt relief-a freedom from the cultural norms that governed our period, the lack of infrastructure and technology needed to cope with our period hygienically, and just the quiet stigma of it. It felt like it was all lifted.' Sometimes the relief was expressed in concrete and specific terms: One Itaukei woman in Fiji said it had taken pressure off her family, as 'pads are expensive and need to be prepared for in time of menses.' She said she normally stayed home to do household duties, so it was challenging for her when she had her menses to go out and buy pads. Brazilian women also spoke of freedom from menstrual discomfort, such as cramps, and the expense of menstrual products. Another woman in Fiji said, 'I can swim with my friends and never have to worry about my monthly friend.'

These internal positive changes are not necessarily perceived externally in these women's communities. Indo-Fijian and Itaukei women say that after menopause, women are seen as old and no longer as valuable in society: 'We are just there to advise but not to participate.' Many in this group worried specifically about their sexual drive and desirability; one said, 'I cannot play my role as wife in satisfying my husband's needs.' However, the men in 
the group stated that women's status and participation in society does not change. This discrepancy could be due to a lack of understanding around menopause. Ironically, none of the male participants expressed a view of menopause as negative or positive; rather, they seemed to see it as a natural part of life. A woman in India, now long past menopause, remembers, 'I had a colleague who had a hysterectomy and therefore hit menopause very young. I remember her husband publicly mocking her, and asking what kind of a woman she was, if she didn't even have her period.'

\section{Learning About Menopause}

Most of our information came from overhearing conversations among the elder women in the house, rather than a focused conversation with our mothers or our doctors. We heard and saw what was happening at home and assumed that it was natural and would happen to us. We didn't make a fuss about these things as you tend to today; menses happens, menopause happens, life goes on for a woman. What's there to talk about? (India)

The quote above from an Indian woman in her mid-70s could easily be Elizabeth's mid-70s mother in the United States or this grandmother in Iran:

My parents never talked about it as they were very conservative and you never speak about this topic, or other similar ones. My mother is still alive but I have no idea when exactly she experienced menopause. There is no education around this in Iran. When it happens you have no idea what is happening to you or how you should tackle it. I am going through it now and my husband has no idea what I'm going through. Although I tell him he just can't grasp the concept or have any understanding towards it.

Although Brazilian women interviewed for this project have learned about menopause through informal conversations among friends and observing the experiences of their close relatives, they, too, say there is 'silence' and 'loneliness' around the topic and they do not feel comfortable talking about it:

We learned about menopause in a very bad way, because we did not even learn from our mother, as their generation also do not know much about it. Even though women are more open today, women generally do not like to say that they are entering on menopause. (Brazil)

I used to hear that our period was going to stop coming at some point around a certain age, however, no one taught me how to handle it. So, I went to search on my own. Only when the symptoms started coming, and my period began to get irregular, did I start searching more about this subject. (Brazil)

Within the Fiji focus group, women reported learning about menopause through different channels. Many Itaukei women had learned about 
menopause through female family members and female friends. While three of the women (two Itaukei and one Indo-Fijian) had learned about it through medical professionals, this was largely due to broader experiences with health professionals regarding their reproductive health. Two women had total hysterectomies and understood their reproductive health more comprehensively compared to other women in the group. Of the 11 female participants, one woman of Indian descent had never learned about menopause and required further education on when and how it begins. Most of the women stated that menopause wasn't widely spoken about and was for women to discuss only. None of the woman had ever spoken about it with male relatives or friends. The older men in the group (46-65) understood that menopause is 'when the bleeding stops' and only knew about it because of their wives' experiences. However, younger men (40-45) stated they had been taught about menopause through secondary education and female relatives. The younger men displayed greater understanding of menopauserelated signs and symptoms compared to their elders.

It is worth noting that the most well-informed in the group had developed knowledge through reproductive health crises. A woman from India also reported hysterectomy as a source of knowledge about menopause: 'About menopause?! Hmm. Probably from the elders in the family, from when they went through menopause. Just this sense that it [periods] would stop, after a certain age.

\section{Continuing Conversations}

Part of the difficulty and challenge of menopausal changes is experiencing and managing them in isolation. Several women in the Fiji group stated that having a supportive husband/partner helped them through menopause, but the interviews and conversations shared from all four nations revealed a great deal of silence around menopause. A woman from Iran currently in perimenopause states, 'I feel absolutely horrified for the journey I have ahead of me. Also I am away from my children so it makes it even more difficult to cope with. On top of that I am caring for my 80 -year-old mother, which makes it even more difficult to get any support for myself.' Her British-Iranian daughter says,

When I speak to my Persian friends about our mothers and menopause, they all say the same thing: "She has gone crazy!" I know we shouldn't talk like that but it's hard to grasp. At least now I know. We are talking more about it. I am trying to be more patient. I also suggested we go see a menopause specialist in London. I am helping her to navigate the health services to help her through it all. The crazy thing is she doesn't talk to any of her friends about it.... You get education from women on these sorts of things-women's bodies and health. ... This is a woman's issue, and we aren't supporting or talking to each other. 
Despite the epithet 'crazy, this quote reflects the transformation in attitude that is possible when people begin to talk about openly about menopause. A single conversation sparked a change in this daughter's response to her mother's menopausal moods and behavior.

\section{Feeling Menopause}

I am going through menopause at the moment. I have become very emotional and I have no control around my emotions-good or bad. Also, on top of that there is this feeling that I am no longer a proper woman. [Iran]

Like this woman from Iran, several women in the Fiji group expressed particular concern regarding the psychological symptoms associated with menopause. Stress and forgetfulness were common, and most worrying: 'Sometimes I just get fed up of doing everything. I am beginning to forget about where I leave things.' One woman linked her depression to the exhaustion she was feeling. All of the men in the group saw mood swings as a sign and symptom in their female partners. Women reported high levels of irritability and a low tolerance toward family members, with one Itaukei woman explaining how difficult this change has been for her. Her children and grandchildren say, 'you angry old woman,' and 'every time you always angry.' This hurt her deeply but she didn't know it was due to menopause, so she was unable to explain her frustration to her family members.

Most of the women interviewed experienced other physical changes as their periods ended: sweating, hot flashes, fatigue, irregular and often heavy periods, migraines, weight fluctuations, and dry skin. Although some expressed these changes were annoying or uncomfortable, they understood that menopause is not itself a disease, and most of the changes are not illnesses. But one of the Brazilian women discussed the difficulty of managing these changes, saying that some women think 'they are ill once they start their menopause process, they think they will die.' The irregular and often heavier periods were cited as particularly troublesome:

I go to the gym, so I use a menstrual cup, but some of my friends find it strange. Due to the lack of information and the right products to deal with heavy flows, some women over this period isolate themselves as they don't want to risk having problems with leakage and so forth. (Brazil)

Two Brazilian participants mentioned having experienced negative physical aspects of menopause, as well as psychological (depression, anxiety) and emotional (PMS, irritability) symptoms. One of the three reported no negative changes and referred to menopause as a very light and uneventful time in her life.

A woman from India reported struggling with physical and emotional changes: 'Physically, I had a lot of symptoms - hot flashes, dryness of skin, 
tiredness, pigmentation. I would cry at the drop of a hat, but also wild mood swings. . . . I think I also felt helpless at things in general then. So, I used this to cry a lot.' When asked if she had learned any cultural practices to ease her discomfort, she said, 'Actually my life coach suggested Evening Primrose tablets. Later my gynecologist prescribed some other tablet, which would help to cope with the fluctuating hormones. But nothing cultural.' Her mother, 21 years older at 76 , chimed in:

We used a lot of Ayurveda to ease our symptoms. It was easy for us. Most of the medicines could be made from herbs in our kitchen gardens, so we could put them together, without telling anyone else, to help ease pain or nausea, or ease hot flashes. I remember telling your sister to have some when she had her hysterectomy. (India)

Many women in the Fiji focus group stated that they felt uncomfortable with their aging bodies as they started managing changes but, with time, have come to accept these changes. How women in Fiji come to understand and respond to menopause appears to be linked with their social status and ethnic background. While Indo-Fijian women frequently sought medical advice for their symptoms, Itaukei women had no routine way of responding to menopausal symptoms. The mother from Iran reported also that women in Iran have few options to manage the physical and emotional changes of menopause, so

[t]hey just internalize it. They don't really do much about it. The doctors don't know much about it so there isn't much to do really. The doctors in the UK have more knowledge and can help, but in Iran we struggle. On a daily basis, well, you pray that it will be a normal day without any unpredicted episodes.

Physical changes, as well as emotional and psychological changes, can impact one's relationships with others. All of the women in the Fiji group experienced fatigue, for instance, affecting their family and work lives. Some worried about the reduction in sexual desire they were feeling, even though they felt good about their periods ending. One of the participants from Brazil mentioned that vaginal dryness was really disturbing her life and significantly affected her sexual life:

With vaginal dryness, it's very painful having sex. As a married woman for many years, I can say that not all husbands are concerned about giving pleasure to their wives in bed, and they [do] not care if their wives are wet enough to have penetra[tive sex]. Many of my friends are embarrassed to buy lubricants because their husbands have prejudice if their wives use such "heretic" products.

As with other physical changes, there is great variation here, too. An Indian grandmother in her seventies said, 'Again it depends. I had a hysterectomy. 
And I could still, you know, be satisfied. It was not difficult. I don't know why people think of them as impossible.'

\section{Changing Menopause Experiences}

$[\mathrm{W}] \mathrm{e}$ need much more education before it happens. I also think we need more empathy for what women go through. It's hard to not understand the changes you go through. There is so much stigma and taboo around menopause in society. It's like menopause is disgusting and whatever happens to women during this time doesn't matter. (Iran)

One of the last questions asked in these informal interviews was some version of, 'What else is important to understand about women's experiences of menopause?' The women from Brazil urged the inclusion of information about menopause along with education about menarche and an end to the medicalization of menopause.

Commonly during the menopause women lose the vaginal muscle tone and they might become incontinent. This kind of information should have been taught to us [when] we were a child. Our vagina is like a muscle like any other, so we could have exercised them to prevent the loss of vaginal tone. By exercising that muscle certainly it would have been more firm during menopause. For us to have a better relationship with menopause, we would need to change our first experience with menstruation, talking more about our body changes and stop sending the message that women should only be mothers.

They also emphasized that everyone's experience is different and that every menstruator should have access to what she needs, although these Brazilian women prefer to see more alternative approaches to help manage menopause.

The Fiji participants all expressed the need for more information about menopause in schools and in the community. One participant said, 'What we need is menopausal preparedness, like they do at schools with menstruation. ... It is easier for young people to get information. Not for women in villages who don't have phones.' They want to see a deeper understanding of what women go through and why. Younger men in the group believe greater knowledge of menopause would help them argue less and communicate more effectively with their female partners. Men in the group expressed interest in attending information sessions on menopause.

\section{Conclusion}

Although we point out common themes and many similarities in these discussions of menopause experiences, we caution readers against generalizing from these stories. None of these women or men represent their countries or even necessarily their specific communities. Their words represent only their own 
individual experiences. Nevertheless, their stories are important and worth sharing.

These stories reiterate to us the importance of making menopause culturally visible. This means representation in the broadest sense, including literary and media representation that tells women's stories of menopause and menopausal women's stories. It also calls for greater openness about menopause in all aspects of life. Our Iranian respondent said, 'Women don't really show the transition to menopause. Our society is not welcoming towards this.' Let's make it welcome, with more talk and more stories. Elizabeth is going to start by sending this essay to Aunt Patricia.

Open Access This chapter is licensed under the terms of the Creative Commons Attribution 4.0 International License (http://creativecommons.org/licenses/ by $/ 4.0 /$ ), which permits use, sharing, adaptation, distribution and reproduction in any medium or format, as long as you give appropriate credit to the original author(s) and the source, provide a link to the Creative Commons license and indicate if changes were made.

The images or other third party material in this chapter are included in the chapter's Creative Commons license, unless indicated otherwise in a credit line to the material. If material is not included in the chapter's Creative Commons license and your intended use is not permitted by statutory regulation or exceeds the permitted use, you will need to obtain permission directly from the copyright holder.

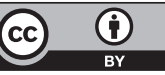

